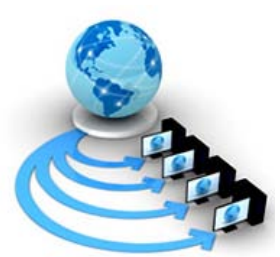

\title{
A STUDY ON ROLE AND APPLICATIONS OF AUGMENTED REALITY IN TOURISM: ITS CHALLENGES AND FUTURE PROSPECTS
}

\author{
Waseem Akram \\ Assistant Professor of Computer Applications \\ Government Degree College Mendhar \\ India
}

\author{
Rakesh Kumar \\ Assistant Lecturer of Computer Applications \\ Government Degree College Mendhar \\ India
}

\begin{abstract}
Augmented reality (AR) innovation, however, is altering the explorer's involvement by influencing the need to travel significantly more consistent, intelligent, and basic. This innovation makes it conceivable to layer computerized improvements over a current reality or genuine situation.

AR innovation additionally changes how one can discover and encounter nearby attractions, culture and excitement. Utilizing applications controlled by AR, Tourists cannot just research and explore to the spots they wish to visit, yet they can encounter them in a considerably more significant path with advanced overlays containing intuitive data about the way of life or history of the site. For instance, when going to a historical center, they can sweep or take photographs of displays, and breathe life into them with AR, with intuitive data and diversions.

AR data frameworks can help voyagers in getting to important data and enhancing their insight with respect to a touristic fascination or a goal, while upgrading the visitor experience and offering expanded levels of diversion all through the procedure. In particular, such data frameworks can customize the conveyance of the multimedia content as per the client's qualities and the utilization setting, subsequently supporting their organization for various situations.

AR innovation is now utilized as a part of various fields for example: arrangement, direction and repeated planning among others. It is likewise utilized inside the tourism division, planning to enhance the traveler encounter. From one perspective, a few cases have demonstrated that AR can help traveler associations and experts towards contacting a more extensive group of spectators by filling in as the conveyance innovation of engaging sight and sound substance and portable applications, fine-tuned to different learning levels.
\end{abstract}

Keywords: Augmented Reality, Current Reality, Tourism, Multimedia, Voyagers, Portable Applications.

\section{INTRODUCTION}

Building an inconceivable guest encounter is fundamental to a goal's prosperity. Augmented reality (AR) has an imperative part to play in this accomplishment as it improves genuine encounters through standard advancements. In 2009, Smartphone applications started to utilize AR innovation to include a layer of direction, substance and excitement to physical areas seen through the telephone's camera. Tuscany+ was the first of these applications manufactured particularly for tourism as an "intelligent, ongoing aide" expected to improve the guest encounter.

AR has turned out to be all the more broadly utilized from that point forward, and has been incorporated into applications for interpretation, expressions of the human experience, instruction, business and that's just the beginning.

Tourism is a blasting industry that empowers individuals to investigate, understanding, and appreciates goals and societies other than their own. As an explorer, one can utilize expanded reality innovation for picking his goals and exercises earlier and keeping in mind that he travel, and at last experience arranging and going in a substantially more intuitive and advancing way that will feel like a voyage all its own.

For tourism, this implies a vacationer can booked the lodging, getting to data while exploring around his goal, deciphering composed or talked signs or discussions, and finding feasting and amusement alternatives should all be possible basically through an application on his cell phones.

\section{AUGMENTED REALITY}

Augmented reality (AR) is one of these forthcoming advancements. It permits the consistent overlay of PC designs onto this present reality with a specific end goal to include additional data and upgrade the view of reality. At last AR will give more data in a more available easy way to use frame. The potential outcomes for the use of this product in the visitor business are huge.

Augmented reality can help in both reasonable and inspiring ways. Initially, it can open your eyes to what's around you. When voyaging, you invest a ton of energy effectively looking both at and for things and AR is an undeniable sidekick for this. It encourages you discover places and sights that may some way or another be dubious. Also, it gives clients another course into getting to travel data." If $\mathrm{AR}$ is put resources into and created it is possible the way we travel could be totally re-imagined.

The combination of advanced data with the client's condition continuously is named as Augmented Reality (AR). [1] Dissimilar to virtual reality, which makes an absolutely counterfeit condition, expanded reality utilizes the current condition and overlays new data over it. The applications for Augmented Reality are composed in unique $3 \mathrm{D}$ programs that enable the designer to tie movement/relevant advanced data in the PC program to an expanded reality marker in this present reality.

For cell phones, the AR applications normally include worldwide situating framework (GPS) to pinpoint the client's area and its extent to recognize gadget introduction. 
[2] The message of AR on cell phones and tablet implies that clients will approach to forward data applicable to their requirements and inclinations. A major issue for travelers is frequently the dialect, as examining and understanding direction, transform into a terrible dream.

AR can decode the diverse dialects by simply checking the dialect showed at airplane terminals, signage and so on. Find out about the way of life and history of a place is the center piece of a visitor's intentions in voyaging. AR has the ability to make a adeptly immersive and enamoring instructive condition. Enabling clients to encounter things as opposed to simply read or be told merits a radical new dimension of learning.

AR can be utilized by the inn and neighborliness industry to give a 360 degree live and intuitive perspective of their rooms to the visitors, empowering a 3D vision.[3] It can be utilized by the flight business to give fliers a more extensive perspective of the seats, their areas, legroom accessible and so on. It can be utilized by the tourism loads up to give continuous perspective of the goals.

\section{INFORMATION}

Visitors are typically individuals in new situations. In this way compactness is critical. The message of AR on advanced mobile phones and tablets implies clients will approach progressive data pertinent to their specific situation. Essential data, for example, portrayals of landmarks or vacation destinations that we would hope to see, showed on sheets could progress toward becoming digitized. Be that as it may, AR could offer an abundance of additional data custom fitted to the person's needs and interests. This thought fits area based administrations, for instance climate figures, Wi-Fi spots, and transport connections could all be shown in the AR. They would likewise approach subjective data, for example, audits on goals, and spots prescribed to their particular territories of intrigue.

AR can assume a key part in tourism industry and a huge change has been acquired by new era cell phones and tablets, which are frequently furnished with GPS sensors, and quick system associations. These gadgets are in this manner ready to help area based AR administrations.[1] A Tourist experience can be interceded by including interactive media and redid substance as indicated by the visitor's needs. Augmented guides are the primary sort of AR application for tourism; an increased guide seeks, recovers and pictures data accumulated from a few Internet sources (e.g., touristic entrances). Data are masterminded keeping in mind the end goal to furnish the clients with all the help important to: sort out voyages, save visits, lease autos, etc [4]. A few increased aides enable the client to stamp and offer POI; in addition, sight and sound substance can be finished by manual explanations and remarks. In the event that the AR application enables the client to share POIs and comments, it is said a social application. For this situation, the effect of AR advancements may be amplified by the Net as clients for the most part request an immediate connection amongst applications and their own particular profiles on interpersonal organizations.

AR applications for tourism and diversion have a solid relationship. [1] In this second kind of AR applications, a visit is sorted out as a multi-level diversion and clients need to explain puzzles and answer questions identified with the visit itself; clients get data about the following phase of the visit just when they can finish the present level. The application demonstrates the client's area and a choice of purposes of enthusiasm for the adjacent region, for example, exhibition halls, eateries and transport's lines. The third kind of AR application for tourism is identified with the idea of fictionalization. For this situation, visitor encounter is expanded alluding to exceptionally unique places, for example, film sets or areas depicted in writing: AR can enhance and improve the fictionalized scene visits. [5]

\section{ROUTE}

Route of these new places, both inside and outside, will be changed. As of now there is a move from utilizing paper maps to GPS frameworks, yet now another move which will see directional bolts superimposed onto our view. Changing way finding was one of the underlying ideas for this innovation and will empower more noteworthy associations with the place.

\section{INTERPRETATION}

Adding to this is the advancement of interpretation programming. The capacity to comprehend signs, menus and other content written in an alternate dialect is synonymous with our capacity to travel effectively. What numbers of us have sat in expectation at a canteen with no thought what we have requested? Applications, for example, Word Lens and Intelligent Eye are spearheading programming which will change over the content from outside to local dialect.

\section{VACATION SPOTS}

There is additionally a place for increased reality inside vacation spots themselves. It will make historical centers and critical structures much additionally captivating spots with far more noteworthy assets for teaching and publicizing.

Finding out about history and culture is a focal piece of vacationers' thought processes in voyaging. AR has the ability to make an intensely immersive and enthralling instructive condition. The intelligent idea of this innovation empowers mental and engine works as it urges clients to react to the data being introduced by the unmistakable interface. By enabling clients to encounter these things instead of simply read or be told a radical new universe of learning is conceivable. Guests will be locked in, upbeat and acquire from their visit, which thusly builds the span of and potential for return visits. Besides, by offering select innovations to clients there is the chance to build ticket costs and increment income.

A model sort of utilization is the Digital Binocular Station (DBS).[6] In light of a customary binocular station and intended for use in galleries, it influences displays to spring up by including a layer of computerized content. This could incorporate unthinkable encounters, for example, reenactments of wiped out creatures or the re-authorizing of noteworthy occasions. This thought has been removed from historical centers and into the city avenues: making shows of 
the city itself. Notable structures and sanctuaries are being recovered surrounding us on advanced mobile phones.

The tourism business has such a large number of potential uses for Augmented Reality that incorporates offering a more noteworthy measure of data to guests, simple interpretation and exact route.[7] Be that as it may, the utilizations don't end there.

Augmented Reality has ended up being an innovation that can give vacationers and nationals obviously, with considerably more customized substance and administrations custom-made to their specific needs. In particular, AR vacationers guides can show content upon ask for as voyagers go around the city, investigating the cityscape and the locales. All things considered, one could state that portable AR applications enable clients to investigate the world by adding new layers to their existence, along these lines bringing about another intuitive and exceptionally unique experience. Also, as these applications are on most (if not all) events got to over cell phones with GPS functionalities; voyagers can increase extra advantages and explore themselves intuitively with the assistance of the immediate explanations of the chose areas. In addition, a versatile AR application, being exceptionally compact, can work as a visitor direct that conveys data upon ask for, in this way limiting from one perspective, the impact of data over-burden and then again the impact of insignificant data. Data over-burden can happen when visitors are overpowered by the transmitted data with respect to recorded locales, gallery displays, the pace of the route et cetera.

At long last, portable AR applications, regardless of whether for vacationer purposes, can be considered as 'social applications', as they offer the likelihood for social cooperation among the different clients getting to them. Therefore, it is certain that applications utilizing the functionalities of AR "must endeavor the novel attributes of cell phones and versatility with a specific end goal to improve and enhance the collaborations permitted"

\section{THE HOSPITALITY SECTOR}

Lodgings, eateries and different administrations intended to encourage sightseers could see incredible advantages. They could move toward becoming spots to visit as opposed to necessities of travel. AR would likewise likely observe a significantly more available and direct correspondence between these administrations and travelers.

Eating is an expansive piece of vacationer industry [8]. Is it a basic action, as well as it is to a great extent imagined that attempting conventional and standard dishes are a major piece of encountering another culture? Guests in an AR improved eatery will have the capacity to communicate with their feasting background. They could choose their own particular subject and alter their table best. They could arrange from a menu which is converted into their own particular dialect and improved with illustrations. They could even perceive how they are readied, client audits, and pick up an understanding into the kitchen.

The potential for AR in the friendliness business could go considerably further. Lodgings could be by put resources into this innovation - at present a significant immature market. They could bring background to what is normally observed as a utilitarian place to lay on a voyage. The
Holiday Inn were first to declare increased reality inside an inn. The thought was that guests could see essentially created Olympic and Paralympics competitors as though they too were occupant in the inn. Basically, they have taken a significant unremarkable piece of the visitor's business and influenced it into an energizing and noteworthy to understanding.

\section{ACCESSIBILITY}

And in addition utilizing the innovation to upgrade the air, handy capacities could be made strides. Presenting AR would mean a more straightforward contact between the client and the administration. Appointments and installments could be made much more effortlessly by means of the innovation - a paperless framework. In addition to the fact that it is less harming to the earth, however it will mean fewer things to bear and less to make sure to take. The vehicle business is spearheading this with cell phones are now being trialed set up of Oyster cards.[9] We are very nearly a considerably more adaptable framework.

\section{PUBLICIZING}

Some portion of drawing in visitors is down to the publicizing technique of the nation. Promoting this new innovation is urgent. Augmented Reality could play a major deliver making new present day style publicizing efforts. [10] By breathing life into adverts on pamphlets and flyers and relating them to the people, clients could pick up a greatly improved impression of their goal or of the fascination they are going to enter. This could be created into a very intense deals strategy considerably more progressed and individual than the dependence of photos and recordings.

This new-age style of showcasing is unfathomably underutilized. However the "Two Treasures 3D Tour" supposedly was an extraordinary achievement. It was intended to furnish potential voyagers with a virtual visit guide of the shorelines and historical centers around Saint Petersburg.[7]

\section{CHALLENGES}

Right now the principle Challenges for this innovation are absence of improvement, absence of learning and in this manner absence of reception by the overall population. Right now the innovation has not achieved the mass market and is in threat of being viewed as gimmicky: it is still seen in a test light instead of as solid programming. Before AR frameworks will turn out to be really promoted issues, for example, readability and following should be created.

Another significant obstruction of versatile AR innovation is the absence of interoperability crosswise over portable stages, an issue similarly influencing application designers and substance aggregators. This recommends despite the fact that there are numerous structures and toolboxes for creating portable applications in light of AR innovation, still these applications can't be utilized over every single working framework.

A fundamental issue influences the spread of $A R$ for tourism: the absence of interoperability among applications; this effect both on engineers and substance aggregators.[11] 
In the event that this issue is shared by all application spaces of enlarged reality, tourism is the one more influenced due to the immense measure of data gatherable.

There are likewise commonsense contemplations: will individuals stroll down the road with their telephone out before them keeping in mind the end goal to explore? Most likely not, Roaming charges feature the significance of disconnected frameworks being made, and some way or another we have to guarantee our gadgets won't come up short on battery, or we will be longing for our solid paperbased frameworks.

Likewise, the AR applications for the vacationer area regularly require an Internet connection. [12] Clearly, this is conceivable through Wi-Fi or 3G. Be that as it may, not all urban areas or locales are completely secured with Wi-Fi systems offering free Internet association and 3G and information meandering charges are as yet an impressive cost for some vacationers, particularly for those of a more youthful age.

This suggests the typical battle between cost, physical size and power. The innovation is now accessible on advanced mobile phones, however to get enough energy to genuinely understand the capability of AR, there will be high cost.

\section{FUTURE PROSPECTS}

Following is one region that has been recognized for advancement. Tom Hall says: "There is an innovation requirement around $\mathrm{AR}$ in that $\mathrm{AR}$ does not yet decipher what it sees. The gadget just "knows" that, at a specific position, a question of X should exist."[13] The innovation is right now in view of GPS information and applying visual data. Later on, ideally we will see programming that really draws in with the encompassing condition. There are many articles that can be utilized as markers in a urban scene; however future advancements will ideally observe the acknowledgment of the innovation in country areas. Jumbled presentations have additionally been perceived as a repeating issue. This is on account of all accessible data is shown unfiltered and henceforth decreases clarity.

Another recommended change is characterizing an arrangement of outline rules for the production of programming. This would mean consistency over all AR applications and would make it significantly less demanding for individuals to utilize. This would be troublesome with various applications and application engineers, for example, mTrip, Nearest Tube, Layar and Wikitude, however their writing computer programs is comparative.[14] It is possible that diverse programming could be converged to make one consistent expanded reality world.

All things considered, future research inside this specific field ought to be centered on the interoperability of structures and toolboxes. It is vital that a cross-stage structure is created - one that will profit designers, specialist co-ops and obviously clients. While an Internet association will dependably be required for extra network purposes or for downloading outer substance, disconnected versatile AR applications are as yet a feasible arrangement. Such arrangements will enable clients to maintain a strategic distance from extra charges without losing anything from a completely customized, intelligent and improved traveler encounter.AR will soon manage the fate of ventures, and travel industry ought to begin as of now.AR can also be helpful for Tourists in

a) Advancement of points of interest and landmarks

b) Intelligent travel guides

c) Connecting with social travel diversions

d) Stunning city visits

e) Continuous bearings

\section{CONCLUSION}

AR can altogether help exhibition halls, legacy locales, urban communities and vacationer experts all in all since data can be composed and transmitted in layers or upon ask. This recommends data can be focused by one's learning level and premiums, age, calling etc.[15] Thus, versatile AR applications can customize the visit, as per visitors' wants and desires, bringing about a considerably more paramount experience. Likewise, data inside an AR application is conveyed using different media designs. Such configurations, as clarified, run from sound and picture to video cuts, 3D models and hyperlinks that may coordinate the client outside the application. The blend of AR innovation, the accessibility of such sight and sound and the watchful plan of the versatile application would altogether be able to enable vacationers to make arrangements of their top choices POIs furnished with inserted data, i.e., the previously mentioned mixed media documents. Further to this, it ought to be noticed that, while geo-area and AR labels may trigger the conveyance of sight and sound substance, the substance itself could be planned in order to give promote network between the AR application and others, therefore offering extra advantages to travelers.

\section{REFERENCES}

[1] M. Federico and S.Andrea , A Survey on Applications of Augmented Reality ACSIJ Advances in Computer Science: an International Journal, Vol. 5, Issue 1, No.19 , January 2016 ISSN : 2322-5157.

[2] R. T. Azuma et al., "A survey of augmented reality," Presence, vol. 6, no. 4, pp. 355-385, 1997.

[3] L. Alem and W. T. Huang, Recent trends of mobile collaborative augmented reality systems. Springer, 2011.

[4] F. P. Brooks Jr, "The computer scientist as toolsmith ii," Communications of the ACM, vol. 39, no. 3, pp. 61-68, 1996.

[5] E. C. Urban, "The information warrior," in Technology and society. Prentice-Hall, Inc., 1999, pp. 493-501.

[6] W. S. Kim, "Virtual reality calibration and preview/predictive displays for telerobotics,” 1995.

[7] M. Billinghurst and A. Dunser, "Augmented reality in the * classroom,” Computer, vol. 45, no. 7, pp. 56-63, 2012.

[8] D. A. Belcher, "Augmented reality, architecture and ubiquity: Technologies, theories and frontiers," Ph.D. dissertation, University of Washington, 2008.

[9] H. Portilla and L. Basanez, "Augmented reality tools for enhanced robotics teleoperation systems," in 3DTV Conference, 2007. IEEE, 2007, pp. 1-4.

[10] S. K. Feiner, A. C. Webster, T. KRUEGER, B. MacIntyre, and E. J. Keller, "Architectural anatomy," PresenceTeleoperators and Virtual Environments, vol. 4, no. 3, pp. 318-325, 1995.

[11] N. R. Hedley, M. Billinghurst, L. Postner, R. May, and H. Kato, "Explorations in the use of augmented reality for geographic visualization,” PRESENCE: Teleoperators and virtual environments, vol. 11, no. 2, pp. 119-133, 2002. 
[12] S. K. Ong, A. Y. Nee, and S. K. Ong, Virtual Reality and Augmented Reality Applications in Manufacturing. SpringerVerlag, 2004.

[13] I. E. Sutherland and C. A. Mead, "Microelectronics and computer science," Scientific American, vol. 237, pp. 210228, 1977.

[14] O. Bimber, R. Raskar, and M. Inami, Spatial augmented reality. AK Peters Wellesley, 2005.

[15] S. M. Land and H. T. Zimmerman, "Synthesizing perspectives on augmented reality and mobile learning,” TechTrends, vol. 58, no. 1, p. 3, 2014.

\section{WEBSITES}

[1] www.google.co.in

[2] http://www.mixedrealitystudio.com/blog/howaugmented-reality-can-enhance-the-tourism-industry/

[3] http://www.investopedia.com/terms/a/augmentedproduct.asp

[4] http://www.scienceandnature.org/IJEMS-Vol4(3)July2013/IJEMS_V4(3)2013-9.pdf

[5] https://destinationthink.com/augmented-reality-tourismexperience/ 